\title{
LENGUA Y CULTURA EN LA OBRA DE EUGENE A. NIDA, LA EQUIVALENCIA DINÁMICA: CRÍTICAS Y DEFENSORES María Elena Fernández-Miranda-Nida
}

Ex directora en la Dirección General de Traducción de la Comisión Europea

\begin{abstract}
In this article we examine the books, lectures and manuscripts of the eminent American translation scholar Eugene A. Nida, in which he speaks of his fieldwork in more than one hundred countries in order to help native translators to render the Bible into their own languages. In doing so, he studied nearly two hundred languages and cultures and explored the deep relationship that exists between culture and language. Given his research in situ, he could develop his theory of dynamic equivalence, which represented a revolution in the approach to translation. Even though this theory was very well received, some detractors have criticized it. Here we review some of these critics and the comments of the authors who have defended Nida's theory. We mention as well some Spanish translation specialists who introduced Nida's ideas into Spain and have been instrumental in their divulgation.
\end{abstract}

KEYWORDS: Culture, Verbal symbols, Sociolinguistics, Dynamic equivalence.

\section{RESUMEN}

En este artículo se examinan los libros, conferencias y manuscritos del eminente traductólogo americano Eugene A. Nida, en los que habla de su trabajo de campo en más de 100 países para ayudar a traductores nativos a traducir la Biblia hacia sus propias lenguas. Esta tarea le llevó a estudiar unas 200 lenguas y culturas y a comprobar la profunda relación que existe entre la cultura y la lengua. Gracias a su investigación in situ, pudo elaborar su teoría de la equivalencia dinámica, que revolucionó el enfoque de la traducción. A pesar de que esta teoría fue generalmente aclamada, también recibió críticas. Aquí se pasa revista a algunas de ellas y a los comentarios de los autores que las han rebatido. También se mencionan los traductólogos españoles que introdujeron las ideas de Nida en España y que han ayudado a difundirlas.

PALABRAS CLAVE: Cultura, Símbolos verbales, Sociolingüística, Equivalencia dinámica.

FECHA DE RECEPCIÓN: 25/02/2016

FECHA DE ACEPTACIÓN: 30/06/2016

PÁGINAS: 23-35 


\section{INTRODUCCIÓN}

En los años 40 la Sociedad Bỉblica Americana había comprobado que las versiones de la Biblia que se habían traducido a la mayoría de las lenguas existentes resultaban incomprensibles para los lectores de muchas lenguas locales. Para averiguar dónde estaba el problema, contrataron al que ya era por entonces un reputado lingüista, Eugene Nida, que había hecho una brillante tesis doctoral en Lingüística en la Universidad de Michigan (USA) con el título «Morphology, the Descriptive Analysis of Words» y se había licenciado en griego antiguo en la Universidad UCLA de Los Angeles con una de las mejores calificaciones en la historia de Estados Unidos, así como en Antropología e incluso en Geología.

Nida comenzó entonces a realizar un trabajo de campo activísimo que duraría casi 50 años, y que le llevó a más de 100 países, estudiando en ellos unas 200 lenguas y culturas. ${ }^{1}$ Enseguida se dio cuenta de por qué nadie comprendía las traducciones de la Biblia hacia esas lenguas, simplemente porque estaban hechas por misioneros ingleses o franceses que no conocían bien el «genio» de la lengua hacia la que traducían, es decir, su estructura, sus expresiones, sus metáforas..., por lo que traducían a partir de sus propias lenguas palabra por palabra. Así lo explica en su manuscrito «My Linguistic Odyssey», uno de los tres que he encontrado en sus archivos tras su fallecimiento:

Las Sociedades Bíblicas habían descubierto que las Escrituras publicadas en lenguas indígenas en Sudamérica y en otras partes del mundo no podían utilizarse. En la mayoría de los casos el problema esencial estaba en que los misioneros habían traducido los textos palabra por palabra, por lo que no se podían comprender ni el léxico ni las construcciones sintácticas [...]

[...] Pronto me di cuenta de que la lengua es solo una parte de la antropología cultural y que las funciones de la lengua no pueden explicarse fuera del contexto de la cultura [...] No podemos pensar en traducción sin combinar la estructura de la lengua con la conducta humana. Una lengua es solo un conjunto de hábitos verbales de conducta y los signos verbales son solo los medios a través de los cuales se representa la realidad. ${ }^{2}$

\section{LENGUA Y CULTURA}

En su trabajo de campo Nida comprobó que la conexión que existe entre la lengua y la cultura, la idiosincrasia, la pertenencia a una misma raza, e incluso a los mismos grupos sanguíneos dentro de una comunidad, es tan importante que dice en este mismo manuscrito:

Siempre me ha sorprendido comprobar el paralelismo que existe entre las lenguas y muchas áreas de la naturaleza, por ejemplo la distribución de los dialectos y la importante correlación entre los grupos sanguíneos de las tribus pigmeas en el Camerún y sus variaciones dialectales - simples modelos paralelos de comunicación verbal y sexual.

También dice sobre su itinerario lingüístico en otro de sus manuscritos, Language and Culture:

Tras haber viajado alrededor del mundo con el fin de ayudar a traductores, he conocido muchas culturas. Fue esencial para mí conocer los valores de los diferentes pueblos para poder comprender cómo se comunican entre ellos [...] En una ocasión estaba revisando una

\footnotetext{
1 Todas las citas literales de este artículo han sido traducidas del inglés por M. Elena Fernández-Miranda-Nida para permitir una lectura más fluida del contenido y de las argumentaciones que en él se hacen. Véanse las peripecias y dificultades que vivió durante este trabajo de campo en Fascinated by Languages. Eugene A. Nida. John Benjamins, Amsterdam/Filadelfia. 2003, págs. 11-65, y en Gene Nida, my busband and my inspiration. Elena Nida. Xulon Press. 2014, pp. 57-62.
}

2 Manuscrito My Linguistic Odissey, págs. 1, 4 y 16. 
traducción del Evangelio de Juan en Yipounou (Camerún), aunque yo no conocía esa lengua. Pero como conocía el francés, enseguida me di cuenta de que la traducción que existía en Yipounou era prácticamente una traducción palabra por palabra de una conocida versión francesa de ese Evangelio. En consecuencia, la población local no podía comprenderla [...] Hasta entonces habían sido los misioneros, en general franceses o ingleses, los que habían tomado las decisiones sobre las traducciones de la Biblia sin consultar con los líderes cristianos locales. Pero había que traducir la Biblia a su lengua, por lo que eran los traductores locales los que tenían que hacer la traducción [...] Sin embargo, los misioneros extranjeros no habían comprendido que una lengua pertenece a su pueblo [...] (Nida, My Linguistic Odissey, p. 1).

En otra ocasión me encontraba en Tetelcingo, México, y estaba reuniendo datos para mi investigación lingüística con un grupo de jóvenes de diferentes tribus. Yo estaba especialmente interesado en las expresiones que utilizaban para enfermedad y muerte. De pronto oímos gritar a algunas personas cerca de un tanque de riego que tenía alrededor de tres metros de profundidad. Alguien debía haberse caído a él. Mis colaboradores y yo corrimos precipitadamente para ver lo que sucedía y algunos de nosotros nos lanzamos al agua, pero la gente del pueblo que había observado la escena desde el principio no se había atrevido a entrar en el agua por miedo a los espíritus malignos que creían que habitaban el tanque. Por fin lo vaciamos para rescatar a la víctima, pero la población local estaba tan asustada que no se atrevía ni a acercarse a él. Es indispensable, pues, tener presentes las creencias de los diferentes pueblos para ayudarles a traducir hacia sus lenguas (Nida, My Linguistic Odissey, p. 10).

Esta fue la vocación esencial de Nida: enseñar a traductores nativos a traducir hacia sus lenguas. Tras su muerte, a finales de 2011, una traductora de Costa de Marfil, Lynell Zogbo, me escribió las siguientes líneas:

Fue un gran hombre y un reconocido académico. Animaba con paciencia a los traductores que acababan de llegar [...] Recuerdo que hablamos de cómo era importante (y posible) presentar y discutir temas difíciles en términos fáciles de comprender [...]

En su magnífico libro Customs and Cultures, Nida expone también las costumbres e ideas de pueblos de diferentes partes del mundo que van a determinar su manera de expresarse. Así dice:

Lo que importa es el valor que una cultura atribuye a las diferentes costumbres y expresiones". 3

En todos sus escritos insiste constantemente en esta idea. Así, en 1994, en una conferencia que dio en el Instituto de Lenguas Modernas y Traductores de la Universidad Complutense, con motivo de los famosos «Encuentros en torno a la traducción» dijo:

El significado de los símbolos verbales en cualquier nivel depende de la cultura de la comunidad que habla esa lengua. La lengua es una parte de la cultura, y de hecho es el conjunto de hábitos más complejo que muestra cualquier cultura. La lengua refleja la cultura y da acceso a la cultura $[\ldots]^{4}$

Y en otra conferencia en los cursos de verano de El Escorial, señaló también:

3 Eugene A. Nida. Customs and Cultures. Harper and Brothers. New York. 1954. Pág. 10.

4 «Encuentros en torno a la traducción». 22-26 febrero 1994. Conferencia publicada en la revista Hieronimus, con el título «Sociolinguistics as a crucial factor in translating and interpreting». P. 43. 
Una lengua es una serie de hábitos verbales que representan aspectos de una cultura. Ningún hablante posee el inventario completo de los signos o de las estructuras de una lengua. La comunidad de los hablantes es la que colectivamente posee, cambia y transmite esa herencia a las generaciones siguientes. Las personas aisladas no pueden preservar una lengua, porque las lenguas constituyen un fenómeno interactivo...

Todas las lenguas reflejan la cultura de la que forman parte...La cultura y la lengua son dos sistemas simbólicos, en la medida en que una lengua consiste en símbolos verbales y la cultura en símbolos constituidos por creencias y prácticas. El hecho de que una lengua es una parte íntima de la cultura indica claramente la necesidad de formular cualquier teoría de la traducción mediante la cultura representada por la lengua... ${ }^{5}$

Nida ha expresado estas ideas en muchas ocasiones, tanto en sus libros como en las innumerables conferencias que ha dado a través del mundo. Así dice también en su libro The Sociolinguistics of Interlingual Communication:

No tiene sentido hablar de las lenguas sin reconocer que solo tienen relevancia dentro de la cultura de la que forman parte 6

Y en una conferencia que dio también en la Universidad Complutense de Madrid sobre el lenguaje figurado, volvió a hacer hincapié en la importancia de las diferentes culturas para comprender las expresiones que se utilizan en las lenguas:

Cuando leemos un texto que describe las experiencias o pensamientos de los llamados pueblos primitivos, nos impresiona la manera que tienen de expresar sus emociones. Estos pueblos no disponen de instrucciones sobre cómo utilizar metáforas, símiles, adagios y proverbios, pero consiguen incorporar en su lenguaje, ya sea oral o escrito, gran cantidad de expresiones figuradas. El lenguaje figurado no es solo patrimonio de los pueblos «civilizados». Los pueblos primitivos describen sus estados mentales y sus emociones a través de sus órganos o de su cuerpo.

Como las diferentes emociones influyen tanto en los latidos del corazón, no es extraño que muchas lenguas representen estados emocionales refiriéndose al corazón. Así, en la lengua miskito (Honduras y Nicaragua) para referirse a la paz dicen «tengo solo un corazón», y para expresar la indecisión «tengo mariposas en el corazón». En tzotzil (México) «un corazón caliente»" significa estar furioso y «tener dolor en el corazón» quiere decir sentir amor. «Contar los latidos del corazón» indica tristeza y «tener sólo un corazón» felicidad; mientras que «tener el corazón asentado» significa tener paz. En quechua la duda se expresa como «tener dos corazones», pero cuando alguien tiene un corazón duro, se dice de él que «no tiene agujeros en el corazón» [...] Y así un largo etcétera.

Pero en otras lenguas, no es el corazón, sino el hígado, la referencia especial para las expresiones figuradas. Por ejemplo en la lengua habbe de África occidental la pena se expresa diciendo que se tiene «el hígado enfermo», y en shilluk, una lengua del Sudán, experimentar gran alegría en las relaciones personales se expresa diciendo «mi hígado se siente muy dulce contigo». En África, la referencia al hígado para describir tanto las emociones positivas como las negativas, se debe probablemente a la importancia de la malaria en este continente, ya que cuando se contrae esta enfermedad hay muchas células muertas en el hígado. En la lengua habbe cuando alguien está preocupado se dice que «su hígado le está buscando». Es muy interesante observar cómo es posible representar con una sola palabra toda una serie de

5 «El desarrollo de una teoría de la traducción», en La traducción en perspectiva. El Escorial. Julio-agosto 1996. Revista Hieronimus, números 4-5 junio 1996-junio 1997, pp. 56 y 61.

6 Eugene A. Nida. Éditions du Hazard. Bruselas. 1996, p. 25. 
estados mentales, emocionales y culturales, como ocurre con el hígado. En la lengua anuak, una típica lengua del Nilo en el Sudán, el hígado es una palabra clave en numerosas expresiones: «su hígado es dulce»: es feliz. «Su hígado es amargo»: es muy insociable. «Su hígado es pesado»: está triste. "Su hígado es poco profundo»": se enfada rápidamente, etc.

También se utiliza en esta lengua la palabra hígado en combinación con verbos: «le ha entrado en el hígado», como en español diríamos le ha entrado en la cabeza, para expresar que lo ha comprendido. «Su hígado se ha asentado»: ya no está preocupado. Pero estas expresiones representan solo una parte de las numerosísimas en las que se recurre al hígado para expresar emociones. ${ }^{7}$

Como conclusión, no me queda más que decir que recomiendo a los traductores que penetren con el máximo interés en la cultura de las lenguas que van a traducir, si no solo producirán textos muertos, es decir palabras sin sentido, cuando la misión del traductor es la de comunicar ideas, es la de dar vida a un texto". ${ }^{8}$

Tras haber estudiado profundamente las lenguas y culturas de tantos pueblos, Nida dice en su libro de memorias Fascinated by Languages que no podemos reducir el estudio de la traducción simplemente a las lenguas más extendidas, sino que también son importantes los textos escritos en las lenguas locales o minoritarias:

La falta de sensibilidad respecto a las formas literarias de una lengua local siempre me ha impresionado.?

Insistía tanto en la necesidad de respetar la cultura que modula la lengua porque había visto miles de traducciones en las que se distorsionaba o se perdía completamente el sentido del mensaje por haber traducido el texto palabra por palabra. En efecto, antes de él abundaban en todas partes, y no solo en lo que se refería a la Biblia, las traducciones en lo que Nida llama «equivalencia formal», es decir, en las que se traducían sustantivos por sustantivos, verbos por verbos, no se reajustaban las unidades gramaticales y se mantenían todos los signos de puntuación ${ }^{10}$.

\section{LA TEORÍA DE LA EQUIVALENCIA DINÁMICA Y SU INFLUENCIA EN EL MUNDO DE LA TRADUCCIÓN}

Dados sus conocimientos lingüísticos y antropológicos y el extraordinario trabajo de campo que realizó, Nida escribió más de 40 libros, y, entre ellos algunos que marcaron un hito y revolucionaron el enfoque de la traducción. Así dice en el manuscrito citado «My Linguistic Odyssey»:

Dada la enorme cantidad de traducciones que se hacen en todo el mundo y la confusión que existe entre los traductores sobre si la traducción es una ciencia, un arte o una habilidad cuando en realidad puede ser las tres cosas - me pareció esencial describir algunos de los principios esenciales y teorías de traducción y relacionarlos con ideas relativas a la teoría de la información, la teoría de la comunicación, la antropología cultural, la sociolingüística, la psycolingüística y la lingüística, lo que hice en el libro Toward a Science of Translating, cuyo

\footnotetext{
7 Véase también, a este repecto, Eugene A. Nida,Toward a Science of Translating. Leiden. Brill 1964. Traducción al español en Sobre la Traducción. Cátedra, 2012, p. 49.

8 Eugene Nida. "Cómo ayudar a los traductores a traducir la cultura». Instituto de Lenguas Modernas y Traductores. Universidad Complutense.Madrid, 2006. No tengo conocimiento de la publicación de esta conferencia, solo conservo el manuscrito.
}

9 Eugene A. Nida.Fascinated by Languages. op. cit., p. 82.

10 Eugene A. Nida,Toward a Science of Translating. Traducción al español en Sobre la Traducción, op. cit., p. 170. 
contenido desarrollé más tarde en The Theory and Practice of Translation ${ }^{11}$, así como en From one Language to Another. ${ }^{12}$

En estos libros expuso y explicó abundantemente su teoría de la «equivalencia dinámica», que describe por primera vez en su libro Toward a Science of Translating de la siguiente manera:

Es el equivalente natural más cercano al mensaje en la lengua de partida (primero en lo que se refiere al significado y luego al estilo) ${ }^{13}$. Esta definición contiene tres términos esenciales: 1 ) equivalente, que apunta al mensaje en la lengua de partida; 2) natural, que apunta hacia la lengua de llegada; y 3) más cercano, que une las dos orientaciones en base al mayor grado de aproximación.

Puesto que la traducción E-D va dirigida principalmente a la equivalencia en la respuesta antes que a la equivalencia en la forma, es importante definir con más exactitud las implicaciones de la palabra natural aplicada a dichas traducciones. Básicamente, la palabra natural debe ajustarse a: 1) la lengua y cultura de la lengua de llegada en su totalidad; 2) el contexto del mensaje específico, y 3) el público de la lengua de llegada.

El total ajuste de una traducción a la lengua y cultura de llegada es un ingrediente esencial en toda traducción estilísticamente aceptable ${ }^{14}$

Sus libros y esta teoría han tenido un impacto extraordinario en los estudios de la traducción, por lo que se le llamó «El patriarca de la traducción» y recibió numerosas distinciones. Dio conferencias en las mejores universidades y fue nombrado Doctor Honoris Causa en algunas de ellas, como en la de Hamilton, Canadá, y en la Universidad Católica de Santiago de Chile. Recibió homenajes en universidades y sociedades lingüísticas de todas partes del mundo, incluida China, en donde enseñó en muchas de sus universidades y a cuya lengua se tradujeron sus libros más importantes.

También ha dejado su legado en la escuela rusa de traducción, donde se le admira mucho. Recientemente Alexander Kalashnikov ${ }^{15}$ ha publicado un artículo en Sendebar, la revista de Traducción de la Universidad de Granada, sobre «Leo Tolstoy's translation of Gospels in light of 20th century Translation Studies» ${ }^{16}$, en el que dice:

Las ideas de Tolstoi anuncian ya algunas tendencias del siglo XX sobre la teoría de la traducción, especialmente en lo que se refiere a equivalencia y pragmática [...] Las críticas y métodos que expone Tolstoi muestran una correlación con las técnicas del siglo XX, especialmente con la teoría de la equivalencia dinámica de Nida.

El análisis del significado que hace Tolstoi recuerda al análisis componencial de Nida, cuando este dice: «análisis componencial es la parte del análisis de un texto cuyo objetivo es descubrir y analizar los componentes semánticos de las palabras» ${ }^{17}$.

11 Eugene A. Nida and Charles R.Taber. The Theory andPractice in Translation. Nida and Taber. Leiden. Brill. 1969. Traducción al español en Sobre la Traducción.

12 P. 8. Jan De Waard y Eugene A. Nida From One Language To Another: Functional Equivalence in Bible Translating. (Nashville, Thomas Nelson, 1986).

En 2001, cuando ya residía en Bruselas, Nida escribió otro libro muy importante sobre el contexto en la traducción: Context in Translation. John Benjamins. The Netherlands.

13 La frase entre paréntesis Nida la añadiría en su libro The Theory and Practice in Translation. Traducción al español en Sobre la traducción. Op. cit., p. 283

14Eugene A. Nida. Toward a Science of Translating. Ttraducción al español en Sobre la traducción. Op. cit., p. 172.

15 National Research University Higher School of Economics, Moscow, Russia.

16Sendebar, No 25. (2014).

17 Sendebar P. 110. Eugene A. Nida and Charles R. Taber. The Theory andPractice of Translation. Traducción al español en Sobre la Traducción. Op. cit., p. 452. 
En su artículo Kalashnikov compara frecuentemente las ideas de Tolstoi con las de Nida. Así afirma lo siguiente en lo que se refiere a traducción cultural:

El componente cultural es una de las nociones claves en los estudios de traducción. De acuerdo con Nida 'la traducción cultural es la traducción en la que se cambia el contenido del mensaje para adaptarlo de alguna manera a la cultura del receptor, y/o en la que se introduce información que no está lingüísticamente implícita en el original. ${ }^{18}$ Algunas metáforas no existen en la cultura de la lengua de llegada o se expresan de forma diferente. La frase de Mateo «O si le pide pescado, ¿le dará una serpiente?» puede parecer absurda a algunos pueblos de África, ya que mucha gente de allí prefiere comer serpiente en vez de pescado. En este caso se recomienda al traductor que busque el nombre de una serpiente no comestible o que haga algún comentario' (Nida). ${ }^{19}$ Tolstoi usaba un provincialismo ruso que significa serpiente en el mismo pasaje. Tolstoi ha representado la traducción cultural mediante omisiones y explicaciones y con elementos de la cultura rusa.

\section{CRÍTICAS Y DEFENSAS DE LA TEORÍA DE LA EQUIVALENCIA DINÁMICA}

Nida ha sido objeto de admiración, pero sus ideas también han recibido críticas. Es evidente que todos los grandes pensadores han recibido tributos de admiración y también críticas, algunas con fundamento y otras no. Precisamente porque sus ideas eran muy impactantes algunos autores han criticado a Nida, bien porque no habían leído sus libros en todo su contexto o porque tenían puntos de vista muy diferentes al no tener su formación antropológica y no haber realizado como él un extenso trabajo de campo. Sin embargo, los grandes traductólogos le han defendido ardientemente. Pero incluso al criticar sus ideas se las hace aún más importantes, ya que de una manera o de otra son sin duda un foco de atención.

Una de las críticas más recientes de la teoría de la equivalencia dinámica de Nida es la de Roland Boer. Boer titula su artículo «El embrollo de la equivalencia dinámica» ${ }^{20}$. Es muy interesante observar cómo siempre hay algún prestigioso académico que responde a las críticas de la obra de Nida. En efecto, en este caso Ernst Wendland y Stephen Pattemore ${ }^{21}$ responden a esta diciendo:

¿Por qué este autor califica la teoría de la equivalencia dinámica de Nida de «embrollo» (caper), o de «una ilícita o ridícula actividad o escapada»?

Piensan que sin duda es porque no ha estudiado seriamente las ideas de Nida en el conjunto de su obra:

La evaluación que Boer hace de la obra de Nida tiene un punto de vista muy limitado y carece de la investigación necesaria. Le falta perspectiva histórica y un conocimiento de lo que han escrito durante las últimas décadas muchos académicos $[\ldots]$

Boer señala en su artículo:

18 Sendebar P. 112. Eugene A. Nida and Charles R. Taber. The Theory andPractice of Translation. Traducción al español en Sobre la Traducción Op. cit., p. 469.

19Eugene A. Nida. Message and mission. The communication of the Christian faith. 1960. William Carey, p. 98.

20 «The dynamic equivalence Capen», en Ideology, Culture and Translation (Ed. Scott S. Elliot and Roland Boer), Atlanta: Society of Biblical Literature, 2012.

21 Wendland (Stellebosch University) and Pattemore (United Bible Societies), "Dynamic", OTE (Old Testament Essays) 26 (2013): Págs. 471-490. 
La equivalencia dinámica (o funcional), como se la conoce, se centra en el mensaje. Todo debe sacrificarse - las palabras, la sintaxis, la gramática - siempre que el texto original se traduzca de manera aceptable en la lengua de llegada. ${ }^{22}$

En primer lugar, como señalan los autores citados, Nida "no era un académico monotemático con solo una 'gran idea", ni nunca dijo que "todo debe sacrificarse". En efecto, en su libro Toward a Science of Translating, Nida dice:

La equivalencia formal es deseable en algunos tipos de traducción. Por ejemplo el lector de los Diálogos de Platón en inglés (o en otra lengua diferente de la original) puede que prefiera una rígida uniformidad en la traducción de los términos clave (como en la traducción de Jowett), que le permitan entender mejor la manera en que Platón utiliza ciertas palabras para desarrollar su sistema filosófico. ${ }^{23}$

Algunos tipos de traducción estrictamente en equivalencia formal tienen un valor limitado, mientras que otras son de gran valor. Así las traducciones de textos especialmente dirigidas a lingüistas, rara vez intentan otra cosa que no sea la proximidad de los significados en equivalencia formal. En dichas traducciones el vocabulario es prácticamente literal e incluso los segmentos están a menudo numerados para que las unidades correspondientes puedan compararse con facilidad.

Por lo que se ha dicho en las secciones precedentes, podría suponerse que la traducción en equivalencia formal ha de ser categóricamente descartada, cuando por el contrario es la traducción perfectamente válida de ciertos mensajes.”24

Y en The Theory and Practice of Translation dice también en este sentido:

La medida en que debe cambiarse la forma para mantener el significado dependerá de la distancia lingüística y cultural entre las lenguas. Naturalmente, las transiciones más fáciles (las que requieren menos cambios formales) son las que se producen al traducir lenguas estrechamente relacionadas, como del portugués al español, o del francés al español (lenguas romances) o del inglés o el holandés al alemán (lenguas germánicas). Además el portugués y el español, lo mismo que el inglés y el alemán pertenecen a un mismo contexto cultural, el tecnológico occidental. Sin embargo, si se traduce del español al húngaro, por ejemplo, los cambios formales serán mayores ya que el húngaro no pertenece a la familia de lenguas indoeuropeas, sino a otra completamente diferente, la fino-ugria. Pero dado que el húngaro forma parte del mismo contexto cultural que el español, los cambios no serán tan grandes.

En cambio, si se traduce del español al hindi, por ejemplo, los cambios formales serán mayores que al traducir del español al húngaro, ya que, aunque el español y el hindi pertenecen a la familia de lenguas indoeuropeas, los contextos culturales, con muchas diferencias en su visión del mundo, son tan diversos que, para mantener el contenido del mensaje, habrá que cambiar mucho más las estructuras formales, tanto gramaticales como léxicas. Por último, al traducir de una lengua como el español al zulú, que pertenece a la familia de las lenguas bantú y que representa una cultura absolutamente diferente, las modificaciones formales deberán ser más numerosas. ${ }^{25}$

22 Boer (2012), «Dynamic Equivalence», p. 13.

23 Eugene A. Nida. Toward a Science of Translating. Traducción al español en Sobre la Traducción. Op. cit., p. 170.

24 Eugene A. Nida. Toward a Science of Translating. Traducción al español en Sobre la Traducción. Op. Cit. Pág. 171. 25 Eugene A. Nida and Charles R. Taber. The Theory and Practice of Translation. Traducción al español en Sobre la Traducción. Op. Cit. Páginas 280-281. 
Boer debería haber interpretado las teorías de Nida en todo su contexto y no en una perspectiva limitada. De todos modos, los puntos de vista de los autores que critican la teoría de la equivalencia dinámica de Nida son necesariamente más restringidos que los de Nida, ya que este realizó un trabajo de campo intensísimo, al estilo de Malinowski, durante casi 50 años, lo que le dio una perspectiva del lenguaje y de la traducción mucho más amplia que la que pueden tener estos críticos, cuyo estudio se redujo a un enfoque teórico y no práctico. Es evidente que cuando se estudian lenguas muy alejadas unas de otras se impone el cambio radical de forma, tanto en palabras, como en sintaxis y gramática. No podemos olvidar tampoco que las distintas culturas crean sus propias expresiones, sus propias metáforas y cuando estas no se pueden entender en la lengua de llegada habrá que cambiarlas. A esto es a lo que se refiere Nida con su teoría de la equivalencia dinámica, algo que se comprende muy bien cuando se leen sus libros en su totalidad y no por párrafos inconexos unos de otros.

Wendland and Pattemore dicen que para evitar distorsionar las ideas de Nida deben leerse sus libros más importantes, y recomiendan la lectura no solo de los clásicos Toward a Science of Translating y The Theory and Practice of Translating, sino también de From One Language To Another. En este último libro Nida dice:

No es justo hablar del texto griego o hebreo (o de una traducción literal de este) comosi se tratara solo de "la forma" y de una traducción más libre como de 'el significado'. Una expresión en cualquier lengua (ya sea de la Biblia o de cualquier lengua de llegada contemporánea) consiste en un conjunto de formas que sirven para indicar el significado en varios niveles: léxico, gramatical y retórico. El traductor debe tratar de emplear un conjunto de formas funcionalmente equivalentes que, en la manera de lo posible, corresponda con el significado del texto original en la lengua de partida. 26

Aunque ya escribió un capítulo en Toward a Science of Translating sobre la función del traductor ${ }^{27}$, en From one Language to Another Nida señala de manera muy precisa cuál debe ser la función de este:

La función del traductor debe ser esencialmente exegética, en el sentido de que la traducción debe reflejar fielmente lo que se dijo, en qué circunstancias y con qué propósito, y debe estar en una forma de la lengua de llegada que no distorsione el contenido o tergiverse el impacto retórico o la emoción que evocan las formas literarias del texto bíblico. ${ }^{28}$

En la sección "La forma como instrumento" de su artículo, Boer dice:

Hablando claramente, Nida ve la forma de una lengua (su sintaxis, gramática, estilo, ritmo, sonido y elementos complejos) de dos maneras: como un medio o instrumento para conseguir la comunicación o como un obstáculo que hay que superar. ${ }^{29}$

Por eso Wendland y Pattemore dicen que para Boer la «equivalencia dinámica tiene una visión de la forma como instrumento».30 Boer dice también que «si la forma de la lengua puede ser un instrumento en ese proceso (la comunicación del mensaje) entonces todo va bien, pero si no, se convierte en un problema que debe plantearse y resolverse». ${ }^{31}$ Respecto a estas afirmaciones Wendland y Pattemore citan el libro Style and Discourse de Nida:

26 Jan De Waard and Eugene A. Nida. From One Language To Another. Op. cit., p. 36.

27Eugene A. Nida. Toward a Science of Translating. Traducción en español en Sobre la Traducción. Op. cit., p. 147.

28J an De Waard and Eugene A. Nida. From One Language To Another. Op. cit., p. 40.

29Roland Boer, «Dynamic Equivalence», p.. 19.

30 Roland Boer, «Dynamic Equivalence», p. 14.

31 Roland Boer, «Dynamic Equivalence», p. 19. 
Es esencial reconocer que el significado de un texto viene indicado por diferentes características, que incluyen sonidos, palabras, construcciones gramaticales y recursos retóricos...

Es imposible evitar las implicaciones de un análisis literario cuando se habla de la Biblia. Si lo hiciéramos robaríamos a las Escrituras su significado dinámico. De hecho, la comprensión de las características de los textos bíblicos (incluido el aspecto formal) solo puede conducir a una mayor consideración de su importancia...

Debemos pensar no solo en cómo traducir de la mejor manera posible una especial característica retórica, sino en cómo compensar la pérdida de impacto incorporando en el texto características retóricas (formales) de la lengua de llegada que pueden no estar representadas específicamente con características correspondientes en el texto original. ${ }^{32}$

Nida ya había señalado en su libro The Theory and Practice of Translationla la necesidad de respetar el genio de cada lengua a la hora de traducir:

Cada lengua posee ciertas características distintivas que le confieren un carácter propio y especial, por ejemplo, en lo que se refiere a la formación de las palabras, a las modalidades de disposición de las frases, a las técnicas para relacionar las oraciones, a los marcadores del discurso y a los tipos especiales de discurso, como poesía, proverbios y canciones [...] Algunas lenguas tienen muchas partículas modales, mientras que otras son especialmente adecuadas para desarrollar un lenguaje figurado."

Para lograr una comunicación efectiva es necesario respetar el genio de cada lengua. Lamentablemente los traductores intentan algunas veces rehacer una lengua. Así ocurrió con un misionero que se empeñó en introducir la voz pasiva del verbo en una lengua de América Latina en la que aquella no existía...Debemos simplemente aceptar que muchas lenguas no tienen voz pasiva y que para expresar acciones emplean solo la activa. El traductor, más que imponer la estructura formal de una lengua a otra, debe estar dispuesto a realizar los cambios formales necesarios para reproducir el mensaje con las formas estructurales propias de la lengua de llegada. 33

La necesidad de respetar el genio de cada lengua al realizar una traducción, fue precisamente lo que condujo a Nida a elaborar su teoría de la equivalencia dinámica o funcional. Como dice de manera tan clara en estos párrafos, al traducir no podemos imponer la estructura de una lengua a otra, sino que debemos realizar los cambios formales necesarios para reproducir el mensaje con las formas propias de la lengua de llegada. La conclusión a la que llega Boer resulta absurda y desproporcionada. Como señalan Wendland y Pattemore, Nida nunca dijo que hubiera que "sacrificar todo", sino que se trata precisamente de no sacrificar las formas esenciales de la lengua de llegada.

Otro defensor de las ideas de Nida es el eminente traductólogo Anthony Pym ${ }^{34}$, que dice sobre la equivalencia dinámica de Nida:

Algunos grandes teóricos de la traducción han atacado a Nida y también muchos de los que no son tan importantes. Casi siempre el ataque se ha centrado en la equivalencia dinámica, como si Nida hubiera afirmado que solo hay una manera legítima de traducir. Pero Nida nunca dijo eso - sino que siempre existe una serie de opciones dentro de las cuales se deben tomar las decisiones. En su contexto histórico, Nida y sus coautores se vieron en la necesidad

\footnotetext{
32 Eugene A. Nida y otros, Style and Discours, with Special reference to the Greek New Testament (Cape Town: Bible Society of South Africa, 1983), pp. 1, 157, 170.

33 Eugene A. Nida and Charles R. Taber. The Theory and Practice of Translation. Traducción al español en Sobre la Traducción. Op. cit., pp. 278-279.

34 Anthony Pym, Intercultural Studies Group. Universitat Rovira I Virgili. Tarragona. Spain.
} 
de combatir el ideal de la fidelidad a la palabra (equivalencia formal) en favor de una evangélica transmisión del espíritu del texto (la fe que está en la base de la equivalencia dinámica.) Criticarle por haber defendido únicamente la equivalencia dinámica representa un enfoque demasiado estrecho e incluso injusto. Su contribución teórica consistió en abrir un espacio conceptual dentro del cual se podía debatir un abanico de opciones de traducción." 35

Creo que también Anthony Pym ha comprendido perfectamente el enfoque de Nida y su contexto intelectual e histórico, sin el que sería imposible interpretar su teoría de la equivalencia dinámica.

En el resumen inicial de su artículo «All things to all people’. On Nida involvement» 36 , Pym dice:

La obra de Eugene Nida ha sido criticada en muchos aspectos. Aquí tratamos de la crítica de tres autores: Y.C. Whang, que afirma que la equivalencia dinámica no puede basarse en las respuestas de los lectores del texto original, ya que esos datos no están disponibles. Por otra parte, Henri Meschonnic acusa a Nida de operar de una manera demasiado binaria, de dividir las opciones en solo dos alternativas que no describen la complejidad de los textos sagrados, y de reducir la traducción a los métodos de marketing. Desde otro punto de vista, Lawrence Venuti describe la equivalencia dinámica como una receta para una ilusoria fluidez, e ideológicamente lamenta el existencialismo humanista de Nida y su vocación misionera ${ }^{37}$. Al analizar estas tres críticas, intentamos indicar la subyacente complejidad de la obra de Nida, y la medida en la que esta permite las múltiples traducciones de los textos bíblicos, basadas en los múltiples puntos de vista subjetivos del misionero [...]

Al comienzo de este artículo Pym señala que durante una conferencia que tuvo lugar en Praga preguntó a Nida: «iNo cree que su preferencia por la equivalencia dinámica sobre la equivalencia formal es una simplificación reductiva?» a lo que Nida respondió: «los dos tipos de equivalencia son dos polos de un abanico de opciones, y algunas veces hay buenas razones para preferir las equivalencias más formales». Pym dice en este artículo que cree que fue una magnífica respuesta.

En efecto, todas las críticas de la obra de Nida se han centrado en su teoría de la equivalencia dinámica, como si Nida hubiera dicho que solo hay una manera legítima de traducir. Esta teoría le ha hecho famoso, y la mayoría de los estudiosos de la traducción la consideran genial, pero como todo lo nuevo y revolucionario también ha sido objeto de controversia.

\section{CONCLUSIÓN}

En mi opinión, las diferentes críticas de Nida no alcanzaron a evaluar sus ideas en su dimensión correcta. La visión de Nida sobre la traducción es necesariamente mucho más amplia y universal, ya que trabajó con cientos de lenguas y culturas. Estudió las costumbres, las actitudes, los miedos y recelos que modulan las diferentes lenguas, y que nosotros, limitados a nuestra cultura occidental, no podemos ni imaginar. Analizó estructuras lingüísticas que no nos son familiares y además enseñó a traducir hacia ellas dos lenguas que están a miles de años de distancia de nosotros, el griego y el hebreo de la Biblia.

$\mathrm{Su}$ aventura intelectual fue grandiosa, su experiencia casi inalcanzable para nuestras mentes. Cuando Nida falleció, periódicos de todo el mundo ensalzaron sus logros. L'Osservatore Romano le llamó un nuevo Jerónimo, y el Wall Street Journal dijo: «Eugene Nida llevó nuevas traducciones de la Biblia a millones de personas, desde el Círculo Polar hasta Asia y las islas del Pacífico».

35 Anthony Pym. «Translation as a future conversation (a defense of Nida)», artículo presentad o en la reunión anual de la Sociedad de Literatura Bíblica, San Diego 17-20 November 2007, que fue una primera versión de «'All things to all people’. On Nida involvement».

36 Septiembre 2008

37 Venuti critica la teoría de la equivalencia dinámica de Nida, pero eso no obsta para que le cite en sus libros aprobando las ideas de Nida sobre otros conceptos. 
También los traductores y académicos españoles le elogiaron antes y después de su muerte. Cuando falleció, un gran traductor de la Dirección General de Traducción de la Comisión Europea, Pollux Hernúñez, escribió su obituario en el periódico español «El País», diciendo:

Entrelazando disciplinas (lingüística, sociosemiótica, antropología, lexicología, teoría de la comunicación), Nida establece el principio de la «equivalencia dinámica» (o funcional), es decir, el equilibrio entre la comprensión del texto original y su correlato en la lengua traducida, teniendo siempre en cuenta los parámetros culturales del lector ${ }^{38}$

El obituario lleva como título «Eugene Nida, maestro de traductores», con lo que reconoce que fue un maestro para todos los traductores, y no solo para los de la Biblia.

También Roberto Mayoral, profesor de la Universidad de Granada, en un homenaje que se hizo a Nida tras su muerte en esta Universidad, dijo:

Si Nida como lingüista fue una figura grandiosa (en gramática, semántica, morfología, sociolingüística, estilística, enfoques estructuralistas y generativos...) en el estudio de la traducción dio pasos gigantescos, hasta el punto de que hoy en día es casi imposible decir algo nuevo que no fuera ya dicho por Nida en alguna de sus obras; cada relectura de sus escritos nos hace ver nuevos aspectos que anteriormente no habíamos detectado. Fue un adelantado a su tiempo hasta extremos inconcebibles: los enfoques pragmáticos y comunicativos, los enfoques funcionales, los profesionales de la traducción como acción profesional dentro de un contexto social, los enfoques cognitivos, la traducción como tecnología... todo ello fue iniciado o intuido por Nida hace medio siglo, cuando la equivalencia interlingüística era la definición corriente de la traducción. Nida sacó al estudio de la traducción de la cárcel del texto y lo paseó por la realidad de sus destinatarios y del acto social y profesional de traducir. ${ }^{39}$

En las facultades de traducción españolas Nida fue aclamado unánimemente. Los traductólogos españoles comprendieron su genio, y sobre todo, lo comprendió desde un primer momento el que fue gran traductor y académico de la lengua, Valentín García Yebra, uno de los primeros intelectuales españoles que difundió con entusiasmo las ideas de Nida en sus libros, en sus conferencias y en sus lecciones magistrales en el Instituto de Lenguas Modernas y Traductores de la Universidad Complutense.

\section{REFERENCIAS BIBLIOGRÁFICAS}

Boer, R. (2012): «The dynamic equivalence caper», en Ideology, Culture and Translation. Ed. Scott S Elliot and Roland Boer. Society of Biblical Literature. Atlanta.

Encuentros en torno a la traducción (1994). 22-26 febrero 1994. Conferencia publicada en la revista Hieronimus. 1994.

Hernuñez, P. (2011). El País. 10 septiembre 2011.

Kalashnikov, A. (2014). «Leo Tolstoy's translation of Gospels in light of 20th century Translation Studies», en Sendebar 25, Universidad de Granada.

Mayoral, R. (2012). Presentación en la Facultad de Traducción de Granada.

Nida, Elena. (2014). Gene Nida, my husband and my inspiration. Xulon Press.

Nida, E. A. (1954). Customs and Cultures. Harper and Brothers: New York.

- (1960). Message and Mission. The communication of the Christian faith. William Carey.

- (1964). Toward a Science of Translating. Leiden: Brill.

- (1986). In Bible Translating. Nashville: Thomas Nelson Publishers.

38 El País, 10 de septiembre de 2011.

39 Presentación en la Facultad de Traducción de Granada. 2012. 
- (1996). The Sociolinguistics of Interlingual Communication. Bruselas: Éditions du Hazard.

- (1996-1997). «El desarrollo de una teoría de la traducción. La traducción en perspectiva». El Escorial. Julio-agosto 1996. Revista Hieronymus Complutensis, números 4-5 junio 1996-junio 1997.

- (2001). Context in Translation. John Benjamins. The Netherlands.

- (2003). Fascinated by languages. John Benjamins: Amsterdam/Filadelfia.

- (2006). «Cómo ayudar a los traductores a traducir la cultura». Instituto de Lenguas Modernas y Traductores. Universidad Complutense. Madrid, 2006. Conferencia inédita.

- (2012). Sobre la Traducción. Cátedra: Madrid. Traducción de M. Elena Fernández-Miranda-Nida.

- «Sociolinguistics as a crucial factor in translating and interpreting».

- Nida, E. A. «Language and Culture». Manuscrito inédito.

- Nida, E. A. «My Linguistic Odyssey». Manuscrito inédito.

Nida, E. A. and De Waard, Jan (1986). From One language To Another: Functional Equivalence in Bible Translating. Nashville: Thomas Nelson Publishers.

Nida, E. A., Louw, J. Snyman, A. and Cronje, van W. (1983). Style and Discourse, with special reference to the Greek New Testament. Cape Town: Bible Society of South Africa.

Nida, E. A. and Taber, Ch. (1969). The Theory and Practice of Translation. Leiden: Brill.

Pym, A. (2007). "Translation as a future conversation (a defense of Nida"). Artículo presentado en la reunión anual de la Sociedad de Literatura Bíblica, San Diego 17-20 November 2007.

- (2008). «All things to all people. On Nida involvement». Septiembre 2008.

Wendland, E. and Pattermore, S. (2013). «Dynamic», OTE 26. 